\title{
Set-valued contractions in b-Metric Spaces with Application
}

\author{
${ }^{1}$ DUANGKAMON KITKUAN, ${ }^{2 *}$ PAKEETA SUKPRASERT \\ ${ }^{1}$ Department of Mathematics, Faculty of Science and Technology \\ Rambhai Barni Rajabhat University, Chanthaburi 22000, THAILAND \\ ${ }^{2}$ Department of Mathematics and Computer Science \\ Faculty of Science and Technology \\ Rajamangala University of Technology Thanyaburi (RMUTT) \\ Thanyaburi, Pathumthani 12110, THAILAND
}

Abstract: -In this article, we present a $(\alpha, F)$-set-valued mapping in setting b-metric space by characterizing the weak contraction condition with the $\mathcal{C}$ function and the $\alpha$-set-valued function of type $S$. There are examples and implementations accessible that illustrate the validity of our findings.

Key-Words: Set-valued mapping, Fixed point, b-metric space, $\alpha$-admissible mapping of type $S$, Nadler's fixed point, Multi-valued, Hausdorff-Pompieu metric

Received: March 24, 2021. Revised: June 12, 2021. Accepted: July 5, 2021. Published: July 26, 2021.

\section{Introduction}

Banach's contraction principle is one of the most useful tools in fixed point theory. Edelstein [1] proved the following version of the Banach contraction principle.

Let $(\mathrm{X}, \mathrm{d})$ be a compact metric space and let $f$ : $X \rightarrow X$ be a self-mapping. Assume that $d(f x, f y)<$ $d(x, y)$ holds for all $x, y \in X$ with $x \neq y$. Then $f$ has a unique fixed point in $X$.

Later, Suzuki [2] proved generalized versions of Edelstein's results in compact metric space as follows.

Let $(X, d)$ be a compact metric space and let $f$ : $X \rightarrow X$ be a self-mapping. Assume that for all $x, y \in$ $X$ with $x \neq y$,

$$
\frac{1}{2} d(x, f x)<d(x, y) \Rightarrow d(f x, f y)<d(x, y)
$$

Then $f$ has a unique fixed point in $X$.

The fixed point theory for set-value mapping was developed after Nadler's famous paper [3].

Let $(X, d)$ be a complete metric space and $f$ be a multi-valued map on $X$ such that $f x$ is a nonempty closed bounded subset of $X$ for any $x \in X$. If there exists $c \in(0,1)$ such that

$$
H(f x, f y) \leq c d(x, y), \quad \forall x, y \in X,
$$

then $f$ has a fixed point in $X$.

Several authors have defined multiple value mapping terms using the concept of the HausdorffPompieu metric. i.e.,

$$
H(A, B)=\max \left\{\sup _{a \in A} d(a, B), \sup _{b \in B} d(A, b)\right\}
$$

where $d(a, B)=\inf \{d(a, b): b \in B\}$. Then $H$ is a metric on $C B(X)$, is the class of all nonempty closed and bounded subsets of $X$.

Aydi et al. [4] introduced a multi-valued mapping in b-metric spaces as follow:

Let $\left(X, d_{b}\right)$ be a complete b-metric space and let $f: X \rightarrow C B(X)$ be a multi-valued mapping such that for all $x, y \in X$,

$$
H(f x, f y) \leq c d_{b}(x, y),
$$

where $0 \leq c<\frac{1}{s^{2}+s}<1$ and

$$
\begin{gathered}
M(x, y)=\max \left\{d_{b}(x, y), d_{b}(x, f x), d_{b}(y, f y),\right. \\
\left.d_{b}(x, f y), d_{b}(y, f x)\right\} .
\end{gathered}
$$

Then $f$ has a fixed point in $X$, that is, there exists $u^{*} \in X$ such that $u^{*} \in f x$.

It is generally expanded or explained in different directions and many (general) fixed point theorems have been identified (see [6, 7, 8, 9, 11, 12, 13, 14, 15]).

In this work, we present a fixed point for $(\alpha, F)$ set-valued mapping in setting b-metric space.

In Section 2, we present definition lemma in bmetric space.

In Section 3, we prove the fixed point theorem for $(\alpha, F)$-set-valued mapping in setting b-metric space and give an example for support our theorem.

In Section 4, we show application are available to demonstrate the reliability of the our result.

\section{Preliminaries}

Definition 2.1. [17, 18] Let $X$ be a nonempty set and 
$s \geq 1$ be a given real number. Take $d_{b}: X \times X \rightarrow$ $[0, \infty)$. Suppose that for all $x, y, z \in X$, we have:

(C1) $d_{b}(x, y)=0$ if and only if $x=y$;

(C2) $d_{b}(x, y)=d_{b}(x, y)$;

(C3) $d_{b}(x, z) \leq s\left[d_{b}(x, y)+d_{b}(y, z)\right]$.

Then, $d_{b}$ is said a b-metric and the triplet $\left(X, d_{b}, s\right)$ is called a b-metric space.

Let $\left(X, d_{b}, s\right)$ be a b-metric space. Let $\left\{x_{n}\right\}$ be a sequence in $X$.

(C1) $\left\{x_{n}\right\} \subseteq X$ converges to a point $u^{*} \in X$ if $\lim _{n \rightarrow \infty} d_{b}\left(x_{n}, u^{*}\right)=0$

(C2) $\left\{x_{n}\right\} \subseteq X$ is Cauchy if, for each $\epsilon>0$, there is some $n(\epsilon) \in \mathbb{N}$ such that $d_{b}\left(x_{n}, x_{m}\right)<\epsilon$ for all $m, n \geq n(\epsilon)$

(C3) $\left(X, d_{b}, s\right)$ is said complete if any Cauchy sequence is convergent in $X$.

Lemma 2.2. [19] Let $\left(X, d_{b}, s\right)$ be a b-metric space with $s \geq 1$. Let $\left\{x_{n}\right\}$ be a sequence in $X$ such that

$$
\lim _{n \rightarrow \infty} d_{b}\left(x_{n}, x_{n+1}\right)=0 .
$$

If $\left\{x_{n}\right\}$ is not a b-Cauchy sequence, then there exist $\epsilon>0$ and $\left\{x_{m(k)}\right\}$ and $\left\{x_{n(k)}\right\}$ two sequences of positive integers such that

(C1) $\epsilon \leq \liminf _{k \rightarrow \infty} d_{b}\left(x_{m(k)}, x_{n(k)}\right) \leq$ $\lim \sup _{k \rightarrow \infty} d_{b}\left(x_{m(k)}, x_{n(k)}\right) \leq s \epsilon ;$

(C2) $\frac{\epsilon}{s} \leq \liminf _{k \rightarrow \infty} d_{b}\left(x_{m(k)}, x_{n(k)+1}\right) \leq$ $\limsup _{k \rightarrow \infty} d_{b}\left(x_{m(k)}, x_{n(k)+1}\right) \leq s^{2} \epsilon$;

(C3) $\frac{\epsilon}{s} \leq \liminf _{k \rightarrow \infty} d_{b}\left(x_{m(k)+1}, x_{n(k)}\right) \leq$ $\limsup _{k \rightarrow \infty} d_{b}\left(x_{m(k)+1}, x_{n(k)}\right) \leq s^{2} \epsilon ;$

(C4) $\frac{\epsilon}{s^{2}} \leq \liminf _{k \rightarrow \infty} d_{b}\left(x_{m(k)+1}, x_{n(k)}\right) \leq$ $\limsup _{k \rightarrow \infty} d_{b}\left(x_{m(k)+1}, x_{n(k)}\right) \leq s^{3} \epsilon$;

Lemma 2.3. [19] Let $\left(X, d_{b}, s\right)$ be a b-metric space with $s \geq 1$. Suppose that $\left\{x_{n}\right\}$ and $\left\{y_{n}\right\}$ are $b$ convergent sequences to $u^{*}$ and $v^{*}$, respectively. Then,

$$
\begin{aligned}
\frac{1}{s} d_{b}\left(u^{*}, v^{*}\right) & \leq \liminf _{n \rightarrow \infty} d_{b}\left(x_{n}, y_{n}\right) \\
& \leq \limsup _{n \rightarrow \infty} d_{b}\left(x_{n}, y_{n}\right) \leq s^{2} d_{b}\left(u^{*}, v^{*}\right) .
\end{aligned}
$$

Lemma 2.4. [20] Let $\left(X, d_{b}, s\right)$ be a b-metric space. For $A \in C L(X)$ and $x \in X$, we have

$$
d_{b}(x, A)=0 \Leftrightarrow x \in \bar{A}=A,
$$

where the closure of the set $A$ is denoted by $\bar{A}$.
Denote by $2^{X}$ (resp. $\left.C L(X)\right)$ the family of subsets (resp. of closed subsets) of $X$. Let $C B(X)$ be the class of all nonempty closed bounded subsets of $X$.

Lemma 2.5. [21] Assume that $f x \in C L(X)$ for each $x \in X$. If $f$ is upper semi-continuous then $G r(f)$ is closed in $X^{2}$.

Definition 2.6. [22] Let $X$ be a nonempty set. Let $f: X \rightarrow X$ and $\alpha: X \times X \rightarrow[0, \infty)$ be two mappings. Let $s \geq 1$ be a given real number. We say that $f$ is weak $\alpha$-admissible of type $S$ iffor $x \in X$ and $\alpha(x, f x) \geq s$, then $\alpha(f x, f f x) \geq s$.

Definition 2.7. [23] Let $X$ be a nonempty set. Given $f: X \rightarrow C L(X)$ and $\alpha: X \times X \rightarrow[0, \infty)$. Let $s \geq 1$ be a given real number. Such that $f$ is said to be $\alpha$-admissible of type $S$ if for each $x \in X$ and $y \in f x$ with $\alpha(x, y) \geq s$, we have $\alpha(y, z) \geq s$ for each $z \in f y$.

Definition 2.8. [24] $A$ mapping $F$ : $[0, \infty) \times$ $[0, \infty) \rightarrow \mathbb{R}$ is called a $C$-class function if it is continuous and for $s, t \in[0, \infty), F$ satisfies the following two conditions:

(C1) $F(r, t) \leq r$;

(C2) $F(r, t)=r$ implies that either $r=0$ or $t=0$.

The family of $C$-class functions is denoted by $\mathcal{C}$.

\section{Main Results}

Definition 3.1. Let $\left(X, d_{b}, s\right)$ be a b-metric space with constant $s \geq 1$ and $f: X \rightarrow C L(X)$ such that $f$ is an $(\alpha, F)$-set-valued mapping if there exist $\alpha: X \times X \rightarrow[0, \infty), F \in \mathcal{C}, \psi \in \Psi, \theta \in \Theta$ and $\phi \in \Phi$ such that

$$
\begin{aligned}
& x, y \in X \text { with } \alpha(x, y) \geq s \\
& \Rightarrow H(f x, f y) \\
& \leq F(\psi(M(x, y))+\theta(N(x, y)), \phi(M(x, y))),
\end{aligned}
$$

where

$$
\begin{aligned}
M(x, y)=\max \{ & d_{b}(x, y), \frac{d_{b}(y, f y)\left[1+d_{b}(x, f x)\right]}{1+d_{b}(x, y)}, \\
& \frac{d_{b}(y, f x)\left[1+d_{b}(x, f y)\right]}{1+d_{b}(x, y)}, \\
& \left.\frac{d_{b}(x, f y)+d_{b}(y, f x)}{2 s}\right\}
\end{aligned}
$$

and

$$
\begin{gathered}
N(x, y)=\min \left\{d_{b}(x, y), d_{b}(x, f x), d_{b}(y, f y),\right. \\
\left.d_{b}(x, f y), d_{b}(y, f x)\right\} .
\end{gathered}
$$


Theorem 3.2. Let $\left(X, d_{b}, s\right)$ be a b-metric space with constant $s \geq 1$ and $f: X \rightarrow C L(X)$ be an $(\alpha, F)$ admissible set-valued mapping. Assume that:

(C1) $f$ is $\alpha$-admissible of type $S$;

(C2) there exist $x_{0} \in X$ and $x_{1} \in f x_{0}$ such that $\alpha\left(x_{0}, x_{1}\right) \geq s$

(C3) $G r(f)$ is a closed subset of $X^{2}$.

Then, f has a fixed point.

Proof. Using condition (C2), we have $x_{0} \in X$ and $x_{1} \in f x_{0}$ such that $\alpha\left(x_{0}, x_{1}\right) \geq s$. If $x_{0}=x_{1}$ or $x_{1} \in$ $f x_{1}$, we deduce that $x_{1}$ is a fixed point of $f$ and hence the proof is done. Now, we assume that $x_{0} \neq x_{1}$ and $x_{1} \notin f x_{1}$. Using Lemma 2.4, $d_{b}\left(x_{1}, f x_{1}\right)>0$. It following equation (2), we have

$$
\begin{aligned}
0 & <d_{b}\left(x_{1}, f x_{1}\right) \\
& \leq H\left(f x_{0}, f x_{1}\right) \\
& \leq F\left(\psi\left(M\left(x_{0}, x_{1}\right)\right)+\theta\left(N\left(x_{0}, x_{1}\right)\right), \phi\left(M\left(x_{0}, x_{1}\right)\right)\right),
\end{aligned}
$$

where

$$
\begin{aligned}
M\left(x_{0}, x_{1}\right) & \\
=\max \{ & d_{b}\left(x_{0}, x_{1}\right), \frac{d_{b}\left(x_{1}, f x_{1}\right)\left[1+d_{b}\left(x_{0}, f x_{0}\right)\right]}{1+d_{b}\left(x_{0}, x_{1}\right)}, \\
& \frac{d_{b}\left(x_{1}, f x_{0}\right)\left[1+d_{b}\left(x_{0}, f x_{1}\right)\right]}{1+d_{b}\left(x_{0}, x_{1}\right)}, \\
& \left.\frac{d_{b}\left(x_{0}, f x_{1}\right)+d_{b}\left(x_{1}, f x_{0}\right)}{2 s}\right\} \\
\leq \max \{ & d_{b}\left(x_{0}, x_{1}\right), d_{b}\left(x_{1}, f x_{1}\right), d_{b}\left(x_{1}, f x_{0}\right), \\
& \left.\frac{d_{b}\left(x_{0}, f x_{1}\right)}{2 s}\right\} \\
\leq \max \{ & d_{b}\left(x_{0}, x_{1}\right), d_{b}\left(x_{1}, f x_{1}\right), \\
& \left.\frac{d_{b}\left(x_{0}, x_{1}\right)+d_{b}\left(x_{1}, f x_{1}\right)}{2 s}\right\} \\
\leq \max \{ & \left.d_{b}\left(x_{0}, x_{1}\right), d_{b}\left(x_{1}, f x_{1}\right)\right\} .
\end{aligned}
$$

Suppose now $\max \left\{d_{b}\left(x_{0}, x_{1}\right), d_{b}\left(x_{1}, f x_{1}\right)\right\} \stackrel{(6)}{=}$ $d_{b}\left(x_{1}, f x_{1}\right)$, then by equation (5) becomes

$$
\begin{aligned}
& d_{b}\left(x_{1}, f x_{1}\right) \\
& \leq F\left(\psi\left(d_{b}\left(x_{1}, f x_{1}\right)\right)+\theta\left(N\left(x_{0}, x_{1}\right)\right), \phi\left(d_{b}\left(x_{1}, f x_{1}\right)\right)\right) .
\end{aligned}
$$

But

$$
\begin{aligned}
& N\left(x_{0}, x_{1}\right) \\
& =\min \left\{d_{b}\left(x_{0}, x_{1}\right), d_{b}\left(x_{0}, f x_{0}\right), d_{b}\left(x_{1}, f x_{1}\right),\right. \\
& \left.\quad d_{b}\left(x_{0}, f x_{1}\right), d_{b}\left(x_{1}, f x_{0}\right)\right\}
\end{aligned}
$$$$
=0 \text {. }
$$

Thus,

$$
\begin{aligned}
0 & <d_{b}\left(x_{1}, f x_{1}\right) \\
& \leq F\left(\psi\left(d_{b}\left(x_{1}, f x_{1}\right)\right), \phi\left(d_{b}\left(x_{1}, f x_{1}\right)\right)\right)
\end{aligned}
$$

Using $\psi(t)<t$ for each $t>0$, we obtain

$$
\begin{aligned}
0 & <d_{b}\left(x_{1}, f x_{1}\right) \\
& \leq F\left(\psi\left(d_{b}\left(x_{1}, f x_{1}\right)\right), \phi\left(d_{b}\left(x_{1}, f x_{1}\right)\right)\right) \\
& \leq \psi\left(d_{b}\left(x_{1}, f x_{1}\right)\right) \\
& <d_{b}\left(x_{1}, f x_{1}\right),
\end{aligned}
$$

which is a contradiction. Hence, $\max \left\{d_{b}\left(x_{0}, x_{1}\right), d_{b}\left(x_{1}, f x_{1}\right)\right\}=d_{b}\left(x_{0}, x_{1}\right)$. Using again equation (5) and the fact that $\psi$ is nondecreasing and $\theta$ is a continuous function, we obtain that

$$
0<d_{b}\left(x_{1}, f x_{1}\right) \leq \psi\left(d_{b}\left(x_{0}, x_{1}\right)\right) .
$$

This implies that there exists $x_{2} \in f x_{1}$ (of course, $x_{2}=x_{1}$ ) such that

$$
0<d_{b}\left(x_{1}, x_{2}\right)<\psi\left(d_{b}\left(x_{0}, x_{1}\right)\right) .
$$

Because $\alpha\left(x_{0}, x_{1}\right) \geq s, x_{1} \in f x_{0}$ and $x_{2} \in f x_{1}$, by the fact that $f$ is $\alpha$-admissible, we have $\alpha\left(x_{1}, x_{2}\right) \geq$ $s$. If $x_{2} \in f x_{2}, x_{2}$ is a fixed point of $f$. Otherwise, $x_{2} \notin f x_{2}$, so we have $d_{b}\left(x_{2}, f x_{2}\right)>0$. It following equation (2), we have

$$
\begin{aligned}
0 & <d_{b}\left(x_{2}, f x_{2}\right) \\
& \leq H\left(f x_{1}, f x_{2}\right) \\
& \leq F\left(\psi\left(M\left(x_{1}, x_{2}\right)\right)+\theta\left(N\left(x_{1}, x_{2}\right)\right), \phi\left(M\left(x_{1}, x_{2}\right)\right)\right),
\end{aligned}
$$

where

$$
\begin{aligned}
& M\left(x_{1}, x_{2}\right) \\
& =\max \left\{d_{b}\left(x_{1}, x_{2}\right), \frac{d_{b}\left(x_{2}, f x_{2}\right)\left[1+d_{b}\left(x_{1}, f x_{1}\right)\right]}{1+d_{b}\left(x_{1}, x_{2}\right)},\right. \\
& \frac{d_{b}\left(x_{2}, f x_{1}\right)\left[1+d_{b}\left(x_{1}, f x_{2}\right)\right]}{1+d_{b}\left(x_{1}, x_{2}\right)}, \\
& \left.\frac{d_{b}\left(x_{1}, f x_{2}\right)+d_{b}\left(x_{2}, f x_{1}\right)}{2 s}\right\} \\
& \leq \max \left\{d_{b}\left(x_{1}, x_{2}\right), d_{b}\left(x_{2}, f x_{2}\right), d_{b}\left(x_{2}, f x_{1}\right),\right. \\
& \left.\frac{d_{b}\left(x_{1}, f x_{2}\right)}{2 s}\right\} \\
& \leq \max \left\{d_{b}\left(x_{1}, x_{2}\right), d_{b}\left(x_{2}, f x_{2}\right),\right. \\
& \left.\frac{d_{b}\left(x_{1}, x_{2}\right)+d_{b}\left(x_{2}, f x_{2}\right)}{2 s}\right\} \\
& \leq \max \left\{d_{b}\left(x_{1}, x_{2}\right), d_{b}\left(x_{2}, f x_{2}\right)\right\} .
\end{aligned}
$$

Similarly as above, we obtain that $\max \left\{d_{b}\left(x_{1}, x_{2}\right), d_{b}\left(x_{2}, f x_{2}\right)\right\}=d_{b}\left(x_{1}, x_{2}\right)$. Using (11) and (12),

$0<d_{b}\left(x_{2}, f x_{2}\right) \leq \psi\left(d_{b}\left(x_{1}, x_{2}\right)\right)<\psi^{2}\left(d_{b}\left(x_{0}, x_{1}\right)\right)$. 
This implies again that there exists $x_{3} \in f x_{2}$ (of course, $x_{3}=x_{2}$ ) such that

$$
0<d_{b}\left(x_{2}, x_{3}\right)<\psi^{2}\left(d_{b}\left(x_{0}, x_{1}\right)\right) .
$$

Because $\alpha\left(x_{1}, x_{2}\right) \geq s, x_{2} \in f x_{1}$ and $x_{3} \in f x_{2}$, by the fact that $f$ is $\alpha$-admissible, we have $\alpha\left(x_{2}, x_{3}\right) \geq$ $s$. If $x_{3} \in f x_{3}, x_{3}$ is a fixed point of $f$. Otherwise, $x_{3} \notin f x_{3}$, so we have $d_{b}\left(x_{3}, f x_{3}\right)>0$. In the same way, we get

$0<d_{b}\left(x_{3}, f x_{3}\right) \leq \psi\left(d_{b}\left(x_{2}, x_{3}\right)\right)<\psi^{3}\left(d_{b}\left(x_{0}, x_{1}\right)\right)$.

By continuing this process, we can construct a sequence $\left\{x_{n}\right\}$ in $X$ such that $x_{n} \notin f x_{n}, x_{n+1} \in$ $f x_{n}, \alpha\left(x_{n}, x_{n+1}\right) \geq s$ and

$$
0<d_{b}\left(x_{n}, f x_{n}\right) \leq d_{b}\left(x_{n}, x_{n+1}\right) \leq \psi^{n}\left(d_{b}\left(x_{0}, x_{1}\right)\right)
$$

for all $n \in \mathbb{N}$. Let $m, n \in \mathbb{N}$ be such that $m>n$. Then,

$$
\begin{aligned}
d_{b}\left(x_{n}, x_{m}\right) & \leq \sum_{i=n}^{m-1} s^{i-n+1} d_{b}\left(x_{i}, x_{i+1}\right) \\
& \leq \sum_{i=n}^{\infty} s^{i} \psi^{i}\left(d_{b}\left(x_{0}, x_{1}\right)\right)
\end{aligned}
$$

Because $\psi \in \Psi,\left\{x_{n}\right\}$ is a Cauchy sequence in the complete b-metric space $\left(X, d_{b}\right)$. Thus, there exists $u^{*} \in X$ such that $u_{n} \rightarrow u^{*}$. Because $x_{n+1} \in f x_{n}$, we have $\left(x_{n}, x_{n+1}\right) \in G r(f)$. The graph is closed, so as $n \rightarrow \infty$, we obtain that $\left(x_{n}, x_{n+1}\right) \rightarrow\left(u^{*}, u^{*}\right)$, with $\left(u^{*}, u^{*}\right) \in G r(f)$. We deduce that $u^{*} \in f u^{*}$, that is, $u^{*}$ is a fixed point of $f$.

Theorem 3.3. Let $\left(X, d_{b}, s\right)$ be a b-metric space with constant $s \geq 1$ and $f: X \rightarrow C L(X)$ be an $(\alpha, F)$ set-valued mapping. Assume that:

(C1) $f$ is $\alpha$-admissible of type $S$ and $\psi, \theta$ are continuous;

(C2) there exist $x_{0} \in X$ and $x_{1} \in f x_{0}$ such that $\alpha\left(x_{0}, x_{1}\right) \geq s$

(C3) if $\left\{x_{n}\right\}$ is a sequence in $X$ with $x_{n} \rightarrow u^{*} \in X$ and $\alpha\left(x_{n}, x_{n+1}\right) \geq s$ for all $n \in \mathbb{N} \cup\{0\}$, then $\alpha\left(x_{n}, u^{*}\right) \geq$ s for all $n \in \mathbb{N} \cup\{0\}$.

Then, $f$ has a fixed point.

Proof. From the proof of Theorem 3.2, there exists a sequence $\left\{x_{n}\right\}$ such that

$$
x_{n+1} \in f x_{n}, x_{n} \notin f x_{n} \text { and } \alpha\left(x_{n}, x_{n+1}\right) \geq s
$$

for all $n \in \mathbb{N} \cup\{0\}$. Next, we will show $\left\{x_{n}\right\}$ is a Cauchy sequence in $X$, which converges to some $u^{*}$ as $n \rightarrow \infty$. Using condition (C3), we obtain

$$
\alpha\left(x_{n}, u^{*}\right) \geq s \text { for all } n \in \mathbb{N} \cup\{0\} .
$$

If $u^{*} \in f u^{*}$, the proof is completed. We assume that $d_{b}\left(u^{*}, f u^{*}\right)>0$. Then

$$
\begin{aligned}
0 & <d_{b}\left(u^{*}, f u^{*}\right) \\
& \leq s\left[d_{b}\left(u^{*}, x_{n+1}\right)+d_{b}\left(x_{n+1}, f u^{*}\right)\right] \\
& \leq s d_{b}\left(u^{*}, x_{n+1}\right)+s H\left(f x_{n}, f u^{*}\right) \\
& \leq s d_{b}\left(u^{*}, x_{n+1}\right) \\
& +s F\left(\psi\left(M\left(x_{n}, u^{*}\right)\right)+\theta\left(N\left(x_{n}, u^{*}\right), \phi\left(M\left(x_{n}, u^{*}\right)\right)\right)\right. \\
& \leq s d_{b}\left(u^{*}, x_{n+1}\right)+s\left[\psi\left(M\left(x_{n}, u^{*}\right)\right)+\theta\left(N\left(x_{n}, u^{*}\right)\right]\right.
\end{aligned}
$$

where

$$
\begin{aligned}
M\left(x_{n}, u^{*}\right) & \\
=\max \{ & d_{b}\left(x_{n}, u^{*}\right), \frac{d_{b}\left(u^{*}, f u^{*}\right)\left[1+d_{b}\left(x_{n}, f x_{n}\right)\right]}{1+d_{b}\left(x_{n}, u^{*}\right)}, \\
& \frac{d_{b}\left(u^{*}, f x_{n}\right)\left[1+d_{b}\left(x_{n}, f u^{*}\right)\right]}{1+d_{b}\left(x_{n}, u^{*}\right)}, \\
& \left.\frac{d_{b}\left(x_{n}, f u^{*}\right)+d_{b}\left(u^{*}, f x_{n}\right)}{2 s}\right\} \\
\leq \max \{ & d_{b}\left(x_{n}, u^{*}\right), d_{b}\left(u^{*}, f u^{*}\right), d_{b}\left(u^{*}, f x_{n}\right), \\
& \left.\frac{d_{b}\left(x_{n}, f u^{*}\right)+d_{b}\left(u^{*}, f x_{n}\right)}{2 s}\right\} \\
\leq \max \{ & d_{b}\left(x_{n}, u^{*}\right), d_{b}\left(u^{*}, f u^{*}\right), d_{b}\left(u^{*}, x_{n+1}\right), \\
& \left.\frac{d_{b}\left(x_{n}, f u^{*}\right)+d_{b}\left(u^{*}, x_{n+1}\right)}{2 s}\right\}
\end{aligned}
$$

and

$$
\begin{aligned}
& \quad N\left(x_{n}, u^{*}\right) \\
& =\min \left\{d_{b}\left(x_{n}, u^{*}\right), d_{b}\left(x_{n}, f x_{n}\right), d_{b}\left(u^{*}, f u^{*}\right),\right. \\
& \left.\quad d_{b}\left(x_{n}, f u^{*}\right), d_{b}\left(u^{*}, f x_{n}\right)\right\} .
\end{aligned}
$$

Taking $n \rightarrow \infty$, we have $\lim \sup _{n \rightarrow \infty} M\left(x_{n}, u^{*}\right) \leq$ $d_{b}\left(u^{*}, f u^{*}\right)$ and $\limsup _{n \rightarrow \infty} N\left(x_{n}, u^{*}\right) \leq 0$. Using the continuity of $\psi$ and $\theta$, we have $\lim \sup _{n \rightarrow \infty} \psi\left(M\left(x_{n}, u^{*}\right)\right) \leq \psi\left(d_{b}\left(u^{*}, f u^{*}\right)\right)$ and $\lim \sup _{n \rightarrow \infty} \psi\left(N\left(x_{n}, u^{*}\right)\right) \leq \psi(0)=0$. Taking $n \rightarrow \infty$ in equation (15), we obtain

$$
0<d_{b}\left(u^{*}, f u^{*}\right) \leq s \psi\left(d_{b}\left(u^{*}, f u^{*}\right)\right)<d_{b}\left(u^{*}, f u^{*}\right),
$$

which is a contradiction. Hence, $u^{*} \in f u^{*}$ and so $f$ has a fixed point.

Corollary 3.4. Let $\left(X, d_{b}, s\right)$ be a b-metric space with a constant $s \geq 1$ and $f: X \rightarrow C L(X)$ be an $(\alpha, F)$ set-valued mapping. Assume that there exist $\alpha: X \rightarrow$ $[0, \infty), \psi \in \Psi, \theta \in \Theta$, and $\phi \in \Phi$ such that

$$
\begin{aligned}
& \alpha(x, y) H(f x, f y)) \\
& \leq F(\psi(M(x, y))+\theta(N(x, y), \phi(M(x, y)))
\end{aligned}
$$

where $M(x, y)$ and $N(x, y)$ were defined by (4) and (5) for all $x, y \in X$. Assume that: 
(C1) $f$ is $\alpha$-admissible of type $S$ and $\psi, \theta$ are continuous;

(C2) there exist $x_{0} \in X$ and $x_{1} \in f x_{0}$ such that $\alpha\left(x_{0}, x_{1}\right) \geq s$

(C3) $\left\{x_{n}\right\}$ is a sequence in $X$ with $x_{n} \rightarrow u^{*} \in X$ and $\alpha\left(x_{n}, x_{n+1}\right) \geq$ s for all $n \in \mathbb{N} \cup\{0\}$, then $\left.\alpha\left(x_{n}, u^{*}\right) \geq s\right)$ for all $n \in \mathbb{N} \cup\{0\}$.

Then, $f$ has a fixed point.

Proof. Using inequality (18) and the contraction (2) holds for all $x, y \in X$ such that $\alpha(x, y) \geq s$. Thus, $f$ is an $(\alpha, F)$-set-valued mapping. Using Theorem 3.3, $f$ has a fixed point.

Corollary 3.5. Let $\left(X, d_{b}, s\right)$ be a b-metric space with constant $s \geq 1$ and $f: X \rightarrow C L(X)$ be an $(\alpha, F)$ set-valued mapping. Suppose there exist $\alpha: X \rightarrow$ $[0, \infty), \psi \in \Psi, \theta \in \Theta$, and $\phi \in \Phi$ such that

$$
\begin{aligned}
& \alpha(x, y) H(f x, f y)) \\
& \leq F(\psi(M(x, y))+\theta(N(x, y), \phi(M(x, y)))
\end{aligned}
$$

$M(x, y)$ and $N(x, y)$ were defined by (4) and (5) for all $x, y \in X$. Assume that:

(C1) $f$ is $\alpha$-admissible of type $S$;

(C2) there exist $x_{0} \in X$ and $x_{1} \in f x_{0}$ such that $\alpha\left(x_{0}, x_{1}\right) \geq s$

(C3) the graph of $f$ is closed.

Then, $f$ has a fixed point.

Proof. Using inequality (19) and the contraction (2) holds for all $x, y \in X$ with $\alpha(x, y) \geq s$. Thus, $f$ is an $(\alpha, F)$-set-valued mapping. Using Theorem 3.3 , the set-valued mapping $f$ has a fixed point.

Corollary 3.6. Let $\left(X, d_{b}, s\right)$ be a $b$-metric space with constant $s \geq 1$ and $f: X \rightarrow X$. Suppose there exist $\alpha: X \times X \rightarrow[0, \infty), F \in \mathcal{C}, \psi \in \Psi, \theta \in$, and $\phi \in$ such that

$$
\begin{aligned}
& x, y \in X \text { with } \alpha(x, y) \geq s \\
& \left.\Rightarrow d_{b}(f x, f y)\right) \\
& \leq F(\psi(M(x, y))+\theta(N(x, y)), \phi(M(x, y))),
\end{aligned}
$$

$M(x, y)$ and $N(x, y)$ were defined by (4) and (5) for all $x, y \in X$. Assume that:

(C1) $\sigma, \eta \in X, \alpha(\sigma, \eta) \geq s$ implies $\alpha(f \sigma, f \eta) \geq s$. Also, $\psi, \theta$ are continuous;

(C2) there exists $\sigma_{0} \in X$ such that $\alpha\left(\sigma_{0}, f \sigma_{0}\right) \geq s$;
(C3) if for $\mu_{0} \in X$, the sequence $\left\{\mu_{n}=f^{n} \mu_{0}\right\}$ in $X$ is such that $f^{n} \mu_{0} \rightarrow \mu \in X$ and $\alpha\left(f^{n} \mu_{0}, f^{n+1} \mu_{0}\right) \geq s$ for each integer $n \geq 0$, then $\alpha\left(f^{n} \mu_{0}, \mu\right) \geq$ s for each $n \geq 0$.

Then, $f$ has a fixed point.

Example 3.7. Let $X=[0, \infty)$ be endowed with the $b$-metric $d_{b}(x, y)=(x-y)^{2}$ with $s=3$ for all $x, y \in$ $X$. Define $f: X \rightarrow C L(X)$ and $\alpha: X \rightarrow[0, \infty)$ by

$$
f x= \begin{cases}{\left[0, \frac{x}{9}\right]} & \text { if } x \in[0,1] \\ {\left[x, x^{2}\right]} & \text { if } x \in(1, \infty)\end{cases}
$$

and

$$
\alpha(x, y)= \begin{cases}3 & \text { if } x \in[0,1] \\ 0 & \text { otherwise. }\end{cases}
$$

Define the functions by $\psi(t)=t, \theta(t)=t$ and $\phi(t)=$ $\frac{80}{81} t$. Take $F(r, t)=r-t$ for all $r, t \in[0, \infty)$.

Firstly, we show that $f$ is $\alpha$-admissible of type $S$. Let $x \in X$ and $y \in f x$ with $\alpha(x, y) \geq s=3$. Then, $x, y \in[0,1]$. Let $u \in f y$, then $u \in\left[0, \frac{y}{9}\right] \subset\left[0, \frac{x}{81}\right] \subset$ $[0,1]$. Then,

$$
\alpha(y, u)=3=s .
$$

Thus, $f$ is $\alpha$-admissible of type S. For $x_{0}=\frac{1}{3}$ and $x_{1}=\frac{1}{9} \in f x_{0}$, we have $\alpha\left(x_{0}, x_{1}\right)=3=s$. For any sequence $\left\{x_{n}=f^{n} x_{0}\right\} \subseteq X$ (where $x_{0} \in X$ is arbitrary) such that $x_{n} \rightarrow u^{*}$ as $n \rightarrow \infty$ and $\alpha\left(x_{n}, x_{n+1}\right)=3=s$ for each $n \in \mathbb{N}$, we have $x_{n}, u^{*} \in[0,1]$, and $\alpha\left(x_{n}, u^{*}\right)=3=$ s for each $n \in \mathbb{N}$.

Next, we will show that the conditions of Theorem 3.3 are fulfilled for all $x, y \in X$ with $\alpha(x, y) \geq s$, that is, $x, y \in[0,1]$ with $x \neq y$. Then,

$$
H(f x, f y)=\frac{(x-y)^{2}}{81} .
$$

Hence,

$$
\begin{aligned}
& H(f x, f y) \\
& =\frac{(x-y)^{2}}{81} \\
& =\frac{1}{81} d_{b}(x, y) \\
& \leq M(x, y) \\
& =F(\psi(M(x, y))+\theta(N(x, y)), \phi(M(x, y))) .
\end{aligned}
$$

All hypotheses of Theorem 3 are satisfied and $f$ has a fixed point.

\section{Application}

Let $X$ be the set of continuous functions specified on the closed interval $[a, b]$. We endow $X$ by the standard b-metric $d_{b}: X \times X \rightarrow[0, \infty):$

$$
d_{b}(x, y)=\left(\sup _{t \in[a, b]}|x(t)-y(t)|\right)^{2},
$$


for all $x, y \in X$. Then, $\left(X, d_{b}\right)$ is a complete b-metric space with constant $s=3$. We consider the following integral equation:

$$
y(r)=y_{0}+\int_{a}^{b} Q(r, t) R(t, y(t)) d t
$$

where $y_{0} \in \mathbb{R}$ and $Q:[a, b] \times[a, b] \rightarrow[0, \infty), R$ : $[a, b] \times \mathbb{R} \rightarrow \mathbb{R}$ are continuous functions. Define $f:$ $X \rightarrow X$ as

$$
f y(r)=y_{0}+\int_{a}^{b} Q(r, t) R(t, y(t)) d t .
$$

Then, a solution of equation (21) is equivalent to stating that the map $f$ has a fixed point.

Theorem 4.1. Assume that the following conditions are satisfied:

(C1) there exists $\alpha: X \times X \rightarrow[0, \infty)$ such that if $\alpha(\sigma, \eta) \geq s=3$ for $\sigma, \eta \in X$, we have for each $t \geq 0$,

$$
\mid R\left(t, \sigma(t)-R\left(t, \eta(t) \mid \leq \sqrt{\ln \left(1+(|\sigma(t)-\eta(t)|)^{2}\right)},\right.\right.
$$

and

$$
\sup _{r \in[a, b]} \int_{a}^{b} Q(r, t) d t \leq 1 ;
$$

(C2) $\sigma, \eta \in X, \alpha(\sigma, \eta) \geq 1$ implies $\alpha(f \sigma, f \eta) \geq 1$;

(C3) there exists $\sigma_{0} \in X$ such that $\alpha\left(\sigma_{0}, f \sigma_{0}\right) \geq s=$ 3 ;

(C4) if $\left\{\mu_{n}=: f^{n} \mu_{0}\right\}$ (where $\mu_{0}$ is arbitrary in $X$ ) is a sequence in $X$ with $\mu_{n} \rightarrow \mu \in X$ and $\alpha\left(\mu_{n}, \mu_{n+1}\right) \geq s$ for each integer $n \geq 0$, then $\alpha\left(\mu_{n}, \mu\right) \geq$ s for each $n \geq 0$.

Then, the integral equation (21) has a solution in $X$.

Proof. For all $\sigma, \eta \in X$, we have

$$
d_{b}(\sigma, \eta)=\left(\sup _{t \in[a, b]}|\sigma(t)-\eta(t)|\right)^{2},
$$

and for $r \in[a, b]$, we obtain

$$
\begin{aligned}
& (|f \sigma(r)-f \eta(r)|)^{2} \\
& =\left(\left|\int_{a}^{b} Q(r, t)\right| R(t, \sigma(t))-R(t, \eta(t))|d t|\right)^{2} \\
& \leq\left(\int_{a}^{b} Q(r, t)|R(t, \sigma(t))-R(t, \eta(t))| d t\right)^{2} \\
& \leq\left(\int_{a}^{b} Q(r, t) \sqrt{\ln \left(1+(|\sigma(t)-\eta(t)|)^{2}\right)} d t\right)^{2} \\
& \leq\left(\int_{a}^{b} Q(r, t) \sqrt{\ln \left(1+d_{b}(\sigma, \eta)\right)} d t\right)^{2} \\
& \leq\left(\int_{a}^{b} Q(r, t) d t\right)^{2} \ln \left(1+d_{b}(\sigma, \eta)\right) \\
& \leq \ln \left(1+d_{b}(\sigma, \eta)\right) .
\end{aligned}
$$

Hence,

$$
\begin{aligned}
& H(f \sigma, f \eta) \\
& \leq \ln \left(1+d_{b}(\sigma, \eta)\right) \\
& \leq \ln (1+M(\sigma, \eta)+N(\sigma, \eta)) \\
& =M(\sigma, \eta)+N(\sigma, \eta) \\
& -(M(\sigma, \eta)+N(\sigma, \eta)-\ln (1+M(\sigma, \eta)+N(\sigma, \eta))) \\
& =F(\psi(M(\sigma, \eta))+\theta(N(\sigma, \eta)), \phi(M(\sigma, \eta))),
\end{aligned}
$$

where $\psi(t)=t, \theta(t)=t$ (it is continuous), $\phi(t)=$ $t-\ln (1+t)$, and $F(s, t)=s-t$. Using condition (C3) and (C4) hold, all hypotheses of Corollary 4 hold. Thus, $f$ has a fixed point, that is, the integral equation (21) has a solution in $X$.

\section{Conclusion}

We introduced the existence and uniqueness of fixed point results for $(\alpha, F)$-admissible set-valued mappings in b-metric spaces using $\mathcal{C}$-functions and $\alpha$ admissible set-valued mappings of type $S$ in this paper. To illustrate the superiority of our results, we provided an example and an application of integral equations.

\section{Acknowledgments}

Firstly, Duangkamon Kitkuan would like to thank the support of the Research and Development Institute of Rambhaibarni Rajabhat University. Finally, Pakeeta Sukprasert was financial supported by Rajamangala University of Technology Thanyaburi (RMUTT).

\section{References:}

[1] M. Edelstein, On fixed and periodic points under contractive mappings. J. Lond. Math. Soc., Vol. 37, 1962, pp. 74-79.

[2] T. Suzuki, A new type of fixed point theorem in metric spaces. Nonlinear Anal., Vol. 71, 2009, 5313-5317.

[3] J. Nadler, Multi-valued contraction mappings. Pac. J. Math. Vol. 30, 1969, pp. 475-488.

[4] H. Aydi, M.F. Bota , E. Karapınar, S. Mitrović, A fixed point theorem for set-valued quasicontractions in b-metric spaces. Fixed Point Theory Appl., 2012., 2012: Article ID 88.

[5] M. Jleli, B. Samet, C. Vetro, F. Vetro, Fixed Points for Multi-valued Mappings in b-Metric Spaces. Abstr. Appl. Anal., 2015, 2015.

[6] M.R. Taskovic, A generalization of Banach's contraction principle.Publications de l'Institut Mathématique, Vol. 23, No. 37, 1978, pp. 179-191. 
[7] D. Gopal, M. Abbas, D.K. Patel, C. Vetro, Fixed points of $\alpha$-type $F$-contractive mappings with an application to nonlinear fractional differential equation. Acta Math. Sci., Vol. 36B, No. 3, 2016, pp. 1-14.

[8] L. Ciric, A generalization of Banach's contraction principle. Proceedings of the American Mathematical Society, Vol. 45, 1974, pp. 267-273.

[9] T. Suzuki, Generalized distance and existence theorems in complete metric spaces. J. Math. Appl., Vol. 253, No. 2, 2001, pp. 440-458.

[10] A. Padcharoen, D. Gopal, P. Chaipunya, P. Kumam, Fixed point and periodic point results for $\alpha$-type F-contractions in modular metric spaces. Fixed Point Theory and Applications, 2016, pp. $1-12$.

[11] A. Padcharoen, P. Kumam, P. Saipara, P. Chaipunya, Generalized Suzuki type $\mathcal{Z}$ contraction in complete metric spaces. Kragujevac Journal of Mathematics, Vol. 42, No. 3, 2018, pp. 419-430.

[12] D. Kitkuan, P. Kumam, V. Berinde, A. Padcharoen, Adaptive algorithm for solving the SCFPP of demicontractive operators without a priori knowledge of operator norms. Analele Universitatii" Ovidius" Constanta-Seria Matematica, Vol. 27, No. 3, 2019, pp. 153-175.

[13] J. Janwised, D. Kitkuan, P. Bunpatcharacharoen, On F- $\alpha$-Geraghty Contractions. Communications in Mathematics and Applications, Vol. 9, No. 4, pp. 627-636.

[14] P. Saipara, P. Kumam, P. Bunpatcharacharoen, Some Results for Generalized Suzuki Type $\mathcal{Z}$ Contraction in $\theta$ Metric Spaces. Thai Journal of Mathematics, 2018, 203-219.

[15] P. Bunpatcharacharoen, S. Saelee, P. Saipara, Modified Almost Type $\mathcal{Z}$-contraction. Thai Journal of Mathematics, Vol. 18, No. 1, 252-260.

[16] D. Jain, A. Padcharoen, P. Kumam, D. Gopal, A new approach to study fixed point of multivalued mappings in modular metric spaces and applications. Mathematics, Vol. 4, No. 3, 2016, pp. 51.
[17] I.A. Bakhtin, The contraction mapping principle in almost metric spaces. Funct. Anal., Vol. 30, 1989, pp. 26-37.

[18] S. Czerwik, Contraction mappings in b-metric spaces. Acta Math. Inform. Univ. Ostrav., Vol. 30, 1993, pp. 5-11.

[19] D. Dukic, Z. Kadelburg, S. Radenovic, Fixed point of Geraghty-type mappings in various generalized metric spaces. Abstr. Appl. Anal. 2011.

[20] B. Samet, C. Vetro, P. Vetro, Fixed point theorems for $\alpha, \psi$-contractive type mappings. Nonlinear Analysis, Vol. 75, 2012, pp. 2154-2165.

[21] S. Hu, N.S. Papageorgiou, Theory. In Handbook of Multivalued Analysis, 1st ed.; Kluwer Academic Publishers: Dordrecht, The Netherlands, 1997

[22] W. Sintunavarat, Nonlinear integral equations with new admissibility types in b-metric spaces. Journal of Fixed Point Theory and Applications, Vol. 18, 2016, pp. 397-416.

[23] H. Qawaqneh, M.S.M Noorani, W. Shatanawi, H. Aydi, H. Alsamir, Fixed point results for multivalued contractions in b-metric spaces and an application. Mathematics, Vol. 7, 2019, pp. 132.

[24] A.H. Ansari, Note on $\phi$ - $\psi$-contractive type mappings and related fixed point. In Proceedings of the 2nd Regional Conference on Mathematics and Applications, Jyvaskyla, Finland, 18-19 September 2014; pp. 377-380.

\section{Creative Commons Attribution License 4.0 (Attribution 4.0 International, CC BY 4.0)}

This article is published under the terms of the Creative Commons Attribution License 4.0

https://creativecommons.org/licenses/by/4.0/deed.en US 